Check for updates

Cite this: Chem. Sci., 2018, 9, 2733

\section{Sequence-dependent attack on peptides by photoactivated platinum anticancer complexes $\dagger$}

\author{
Christopher A. Wootton, (D) Carlos Sanchez-Cano, (D) Andrea F. Lopez-Clavijo, \\ Evyenia Shaili, (D) Mark P. Barrow, (D) Peter J. Sadler (D)* and Peter B. O'Connor (D)*
}

Received 3rd December 2017 Accepted 1st February 2018

DOI: $10.1039 / \mathrm{c} 7 \mathrm{sc} 05135 \mathrm{~b}$

rsc.li/chemical-science
Octahedral platinum(Iv) complexes such as trans,trans,trans- $\left[\mathrm{Pt}\left(\mathrm{N}_{3}\right)_{2}(\mathrm{OH})_{2}(\mathrm{pyridine})_{2}\right]$ (1) are stable in the dark, but potently cytotoxic to a range of cancer cells when activated by UVA or visible light, and active in vivo. Photoactivation causes the reduction of the complex and leads to the formation of unusual Pt(॥) lesions on DNA. However, radicals are also generated in the excited state resulting from photoactivation (J. S. Butler, J. A. Woods, N. J. Farrer, M. E. Newton and P. J. Sadler, J. Am. Chem. Soc., 2012, 134, 16508-16511). Here we show that once photoactivated, 1 also can interact with peptides, and therefore proteins are potential targets of this candidate drug. High resolution FT-ICR MS studies show that reactions of 1 activated by visible light with two neuropeptides Substance P, RPKPQQFFGLM-NH (SubP) $^{2}$ and $[\mathrm{Lys}]^{3}$-Bombesin, pEQKLGNQWAVGHLM-NH 2 (K ${ }^{3}$-Bom) give rise to unexpected products, in the form of both oxidised and platinated peptides. Further MS/MS analysis using electron-capture dissociation (ECD) dissociation pathways (enabling retention of the Pt complex during fragmentation), and EPR experiments using the spin-trap DEPMPO, show that the products generated during the photoactivation of 1 depend on the amino acid composition of the peptide. This work reveals the multitargeting nature of excited state platinum anticancer complexes. Not only can they target DNA, but also peptides (and proteins) by sequence dependent platination and radical mechanisms.

\section{Introduction}

Diazido platinum(Iv) complexes such as trans,trans,trans$\left.\left[\mathrm{Pt}\left(\mathrm{N}_{3}\right)_{2}(\mathrm{OH})_{2} \text { (pyridine) }\right)_{2}\right]$ (1) are promising agents for use in Photo-Activated Chemotherapy (PACT), ${ }^{\mathbf{1}, 2}$ which offers potential temporal and spatial control over their activity, ${ }^{3-5}$ reducing side effects through unwanted attack on normal tissues. ${ }^{6,7}$

Complex 1 (scheme 1) and its analogues exhibit little activity in the dark, yet possess potent antiproliferative activity in vitro against a wide range of cancer cells upon irradiation with visible light, ${ }^{8}$ and are also active in vivo towards oesophaegeal cancer after short time exposures to blue light. ${ }^{9}$ Furthermore, they do not rely on the conversion of ${ }^{3} \mathrm{O}_{2}$ to ${ }^{1} \mathrm{O}_{2}$ to kill cancer cells, as sensitisers used in photodynamic therapy (e.g. based on tetrapyrroles), ${ }^{10}$ which potentially can allow them to function effectively under the hypoxic conditions found in tumors. ${ }^{7,11,12}$

Complex 1 is more active than its cis isomer, and not cross resistant with cisplatin. ${ }^{8}$ Its mechanism of action seems to involve the platination of DNA by Pt(II) photoproducts, forming inter-strand DNA cross-links, which are more difficult to repair

Department of Chemistry, University of Warwick, Gibbet Hill Road, Coventry CV4 7AL, UK. E-mail: p.oconnor@warwick.ac.uk; p.j.sadler@warwick.ac.uk; Fax: +44 (0)24 76151009; +44 (o)24 765 23819; Tel: +44 (o)24 76151008; +44 (0)24 76523818

$\dagger$ Electronic supplementary information (ESI) available: Detailed MS data and discussion of effects of $\mathrm{Pt}$ on MS/MS fragmentation, as Scheme S1, Tables S1-S14 and Fig. S1-S10. See DOI: 10.1039/c7sc05135b than DNA-adducts formed by cis-analogues. ${ }^{\mathbf{1 1}}$ However, radicals are also generated during irradiation of the complex with visible light. ${ }^{\mathbf{1 , 6 , 1 3 , 1 4}}$ Initially it was believed that the mechanism of photodecomposition of $\mathbf{1}$ simply involved excitation of the ligand(azide)-to-metal $\left(\mathrm{Pt}^{\mathrm{IV}}\right)$ charge-transfer band, with oneelectron transfer from each azide ligand giving rise to $\mathrm{Pt}^{\mathrm{II}}$ and two azidyl radicals which can combine to form three molecules of $\mathrm{N}_{2} \cdot{ }^{1}$ However, the detailed photodecomposition pathways are complex, can lead to the production of azidyl radicals, singlet

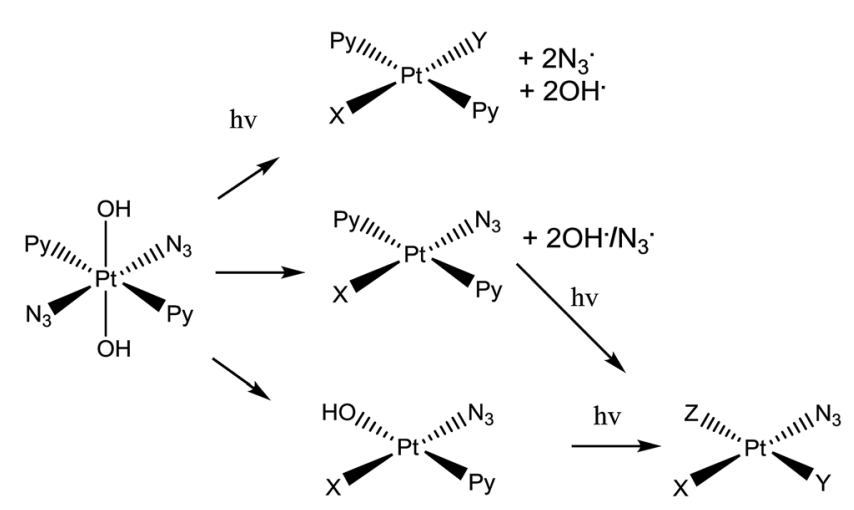

Scheme 1 Trans, trans, trans- $\left[\mathrm{Pt}\left(\mathrm{N}_{3}\right)_{2}(\mathrm{OH})_{2}(\mathrm{py})_{2}\right]$ (complex 1), the photo-activatable prodrug used in this study, along with illustrative photo-decomposition pathways leading to $\mathrm{Pt}^{\prime \prime}$ products which can form bonds/inter-strand cross-links on DNA. ${ }^{1}$ 
oxygen (even in absence of gaseous $\mathrm{O}_{2}$ ), nitrenes, and hydroxyl radicals, ${ }^{\mathbf{1 , 6 , 1 3 , 1 4}}$ and depend strongly on the biomolecules present. For example, loss of $\mathrm{N}_{2}$ from a bound azide can lead to nitrene intermediates which might attack thioethers such as the side-chain of methionine. ${ }^{15}$ Additionally, the production of azidyl radicals is quenched in the presence of tryptophan (but not other amino acids such as glycine or tyrosine). ${ }^{\mathbf{1 4}}$ This suggests that 1 might interact with peptides and proteins inside cells, following different photodecomposition pathways depending on their sequences. However, the interaction of photoactivated 1 with peptides has yet to be studied.

Tandem mass spectrometry (MS/MS) analysis has been successful in studying an array of peptides and proteins while retaining vital post-translational modifications (PTM's). ${ }^{16-18}$ This technique has been used to investigate the interactions of biomolecules with platinum drugs such as cisplatin, ${ }^{19-21}$ transplatin, ${ }^{22}$ oxaliplatin, ${ }^{23}$ or diiodido-platinum complexes, ${ }^{24}$ but also ruthenium, ${ }^{25-28}$ and organometallic iridium and osmium complexes. $^{29,30}$ Electron-based dissociations are particularly useful when studying metallodrug interactions where the topdown approach has allowed the characterisation of entire protein sequences and the unambiguous determination of multiple binding sites for metallodrugs on various proteins, ${ }^{21,31-33}$ without further chemical modifications such as digestion which can disrupt/dissociate modifications. Electron capture dissociation (ECD) MS/MS is particularly effective for PTM analysis due to its non-ergodic character ${ }^{34}$ and its ability to fragment species without loss of fragile PTM's. ${ }^{35}$

Herein, we use ultra-high resolution Fourier Transform Ion Cyclotron Resonance Mass Spectrometry (UHR-FT-ICR MS) to study the interaction of trans,trans,trans-[ $\mathrm{Pt}\left(\mathrm{N}_{3}\right)_{2}$ $(\mathrm{OH})_{2}$ (pyridine) $)_{2}$ (1) with two model peptides (neuropeptides); Substance P, RPKPQQFFGLM-NH ${ }_{2}$ (SubP), and [Lys] $]^{3}$-Bombesin, pyrQKLGNQWAVGHLM-NH (K $^{3}$-Bom). Both of which have amidated C-termini. Our experiments show for the first time that photoactivation of $\mathbf{1}$ leads to both amino-acid-specific platination and oxygenation of peptides.

\section{Results and discussion}

$\mathbf{K}^{\mathbf{3}}$-Bom and SubP are naturally occurring peptides with a role in some types of cancer; $\mathbf{K}^{\mathbf{3}}$-Bom is a known tumour marker, ${ }^{36}$ and SubP has elevated levels in several types of cancer cells. ${ }^{37}$ Initial experiments showed that the use of bright red light during sample preparation and analysis had no effect on 1, while low levels of white light induced the photoactivation of the complex. Therefore, all samples were prepared and analysed in darkness or with very low levels of red light, to avoid activation of $\mathbf{1}$ prior to irradiation with blue light.

Photoactivation of $\mathbf{1}$ in presence of SubP or $\mathbf{K}^{\mathbf{3}}$-Bom was first followed using UV-vis spectroscopy (Fig. S1†). Complex 1 exhibits an intense azide-to-Pt(Iv) charge-transfer band $\left(\lambda_{\max }=\right.$ $295 \mathrm{~nm}$ ) which can be used to monitor the photodecomposition of the complex. ${ }^{1}$ SubP had little apparent effect on the rate of decomposition of $\mathbf{1}$. However, $\mathbf{K}^{\mathbf{3}}$-Bom slowed this process, and induced the formation of a new peak at ca. $250 \mathrm{~nm}$.
Using nESI-FT-ICR-MS, we analysed reaction mixtures of 1+SubP and $\mathbf{1}+\mathbf{K}^{\mathbf{3}}$-Bom (0.5-1 drug: peptide) irradiated with blue light (463 nm; 30-120 min) to activate 1. Peaks for a total of 8 and 12 products were assigned for the reactions of $\mathbf{1}+\mathbf{S u b P}$ and $\mathbf{1}+\mathbf{K}^{\mathbf{3}}$-Bom, respectively (Fig. 1, Table $\mathrm{S} 2 \dagger$ ). Most can be assigned to different platinated adducts of the peptides. For the reaction between 1+SubP, only mono-platinated adducts were observed, containing the modifications $\left\{\mathrm{Pt}(\mathrm{py})(\mathrm{OH})\left(\mathrm{N}_{3}\right)\right\},\left\{\mathrm{Pt}(\mathrm{py})_{2}\left(\mathrm{~N}_{3}\right)\right\}$, $\left\{\mathrm{Pt}\left(\mathrm{N}_{3}\right),\right\}$, and $\left\{\mathrm{Pt}(\mathrm{py})_{2}\right\}$ with reasonable intensity, and $\left\{\mathrm{Pt}(\mathrm{py})_{2}(\mathrm{OH})\right\}$ at low intensity. However, analysis of the reaction $\mathbf{1}+\mathbf{K}^{\mathbf{3}}$-Bom showed both mono- and di-platinated adducts, containing $\left\{\mathrm{Pt}(\mathrm{py})_{2}\right\},\left\{\mathrm{Pt}(\mathrm{py})_{2}\left(\mathrm{~N}_{3}\right)\right\},\left\{\mathrm{Pt}(\mathrm{py})_{2}(\mathrm{OH})\right\}$, and both $\left\{\mathrm{Pt}(\mathrm{py})_{2}\right\}$ and $\left\{\mathrm{Pt}(\mathrm{py})_{2}\left(\mathrm{~N}_{3}\right)\right\}$ modifications simultaneously.

Interestingly, both unmodified and platinated adducts of the peptides were found to be oxidised when irradiated in presence of 1. SubP species had the addition of one oxygen (by exact mass), while up to three oxygen atoms were found on $\mathbf{K}^{\mathbf{3}}$-Bom species. Similar species were not observed upon irradiation of the peptides in absence of $\mathbf{1}$, or when $\mathbf{1}+$ peptide mixtures where not irradiated with blue light.

\section{Photoactivated platination of $[\mathrm{Lys}]^{3}$-Bombesin}

Platinum-containing $\mathbf{K}^{\mathbf{3}}$-Bom adducts were readily identified in MS and MS/MS spectra by platinum's characteristic isotopic pattern (Fig. 1, inset). Clear peaks for various platinated species can be observed simultaneously, showing release of 1-2 hydroxido ligands and 1-2 azido ligands. Retention of the

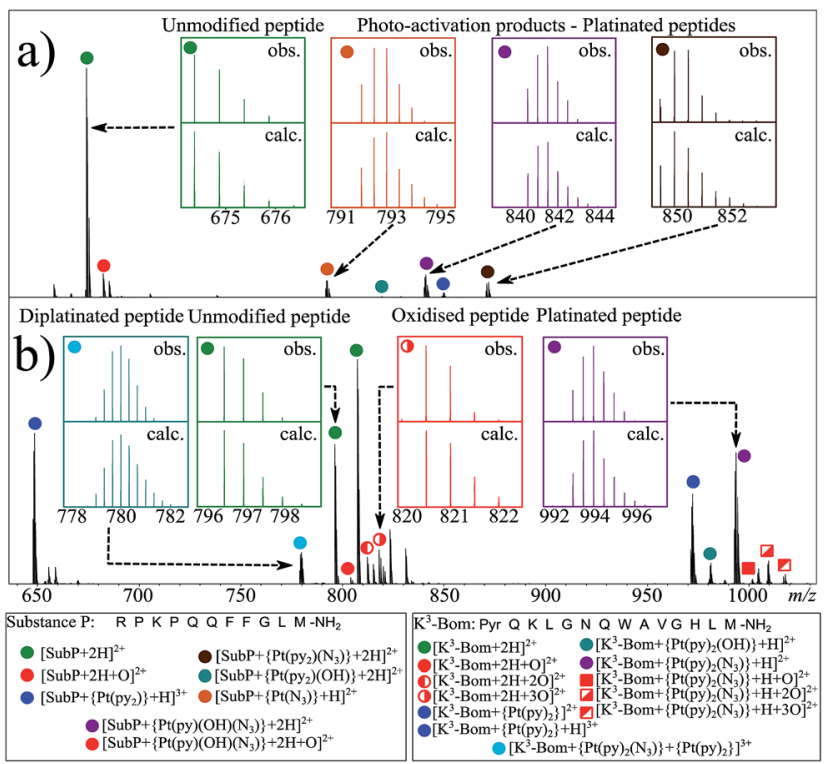

Fig. $1 \mathrm{nESI} F \mathrm{FT}-\mathrm{ICR}$ mass spectra of (a) ca. $1 \mu \mathrm{M}$ aqueous complex $1+$ SubP, and (b) complex $1+\mathrm{K}^{3}$-Bom reaction mixtures $(0.5: 1$ drug : peptide ratio) after 1 and $2 \mathrm{~h}$ of irradiation (respectively) with blue visible light $(463 \mathrm{~nm})$. Inset; various isotopic patterns for the observed (obs.) and calculated (calc.) species assigned from the mass spectra - showing the influence of platinum on observed isotopic distributions. Green filled circles indicate unmodified peptide species, red indicates oxidised species (both peptide and platinated peptides), other colours indicate platinated peptide species with different $\mathrm{Pt}(॥)$ based modifications 
pyridine ligands during the photoactivation of 1 correlates well with previous ${ }^{1} \mathrm{H}$-NMR experiments on model reactions with guanine derivatives, ${ }^{6,11}$ as do products in which one azido ligand remains bound in the case of the $\left\{\mathrm{Pt}(\mathrm{py})_{2}\left(\mathrm{~N}_{3}\right)\right\}^{+}$modification. ${ }^{6}$

ECD MS/MS analysis of the platinated $\mathbf{K}^{3}$-Bom species is summarised in Fig. 2. Full assignment lists and ECD MS/MS spectra are in Tables S2-S4 and Fig. S2. $\dagger \mathbf{K}^{3}$-Bom contains methionine, histidine and lysine residues, all potential $\mathrm{S}$ or $\mathrm{N}$ donor ligands. Pt(II) complexes are known to bind preferentially at the $\mathrm{S}$ of Met, followed by His N. ${ }^{20,32,38-40} \mathrm{Pt}-\mathrm{S}$ bonds are usually strong, and survive harsh $\mathrm{pH}$ digestions and high energy gas phase dissociations in tandem MS experiments. ${ }^{20}$ However, $\left\{\mathrm{Pt}(\mathrm{py})_{2}\left(\mathrm{~N}_{3}\right)\right\}^{+}$and $\left\{\mathrm{Pt}(\mathrm{py})_{2}(\mathrm{OH})\right\}^{+}$modifications from monoplatinated $\mathbf{K}^{3}$-Bom adducts were unambiguously bound at the $\mathrm{His}^{12}$ residue, despite the C-terminal Met. ${ }^{14} \mathrm{MS} / \mathrm{MS}$ analysis of $\left[\mathbf{K}^{3} \text {-Bom }+\mathrm{Pt}(\mathrm{py})_{2}\right]^{2+}$ species yielded no sequence-informative fragments, only ligand and/or amino acid side chain loss peaks. Such behaviour has been attributed to extended cyclic structures which can disrupt usual MS/MS fragmentation. ${ }^{41}$ However, the presence of metal centres presents unique challenges to MS and MS/MS peptide/protein analysis. ${ }^{41-44}$

The charged Pt centre altered the ECD MS/MS fragmentation pattern by providing a fixed charge at the point of interaction (e.g. His ${ }^{11}$ of $\mathbf{K}^{3}$-Bom), but also enhanced side chain losses of amino acid groups present. Electron capture at the $\mathrm{Pt}^{\mathrm{II}}$ centre/ electron transfer of previously captured electrons on the peptide also caused additional ligand loss from the bound complex and additional fragmentations from amino acid residues, including unique side chain losses from methionine residues (Scheme S1†). CAD MS/MS of platinum complex-containing species caused gas-phase dissociation of the platinum-bound ligands, even at low energies $(<5-7 \mathrm{~V})$, creating a reactive $\mathrm{Pt}^{\mathrm{II}}$ centre, which quickly cyclised with available peptide groups and produced uninformative fragmentation spectra.

Still, ECD MS/MS of $\left[\mathbf{K}^{3}-\mathbf{B o m}+\mathrm{Pt}(\mathrm{py})_{2}+\mathrm{H}\right]^{3+}$ species produced abundant backbone fragmentation (Fig. S2c广). This showed simultaneous binding at $\mathrm{His}^{12}$ and $\mathrm{Met}^{14}$ residues of $\left\{\mathrm{Pt}(\mathrm{py})_{2}\right\}$ photoproducts, producing a small cyclic region in the modified peptide species.

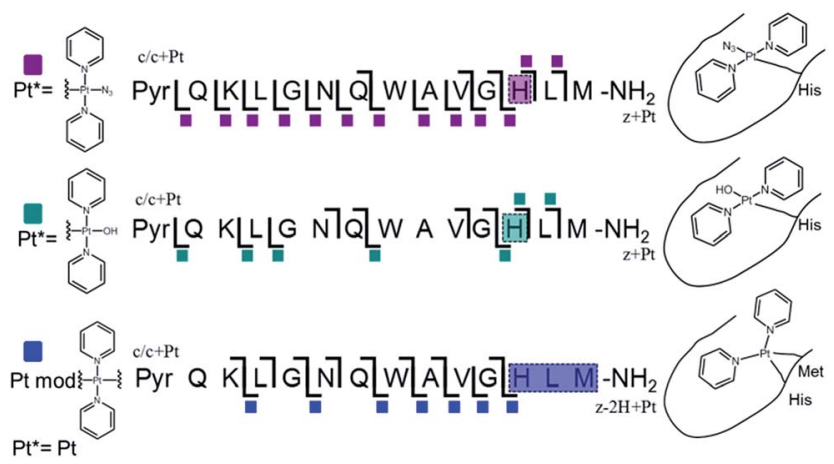

Fig. 2 Platinated $\mathrm{K}^{3}$-Bom peptide species observed and fragmented by ECD MS/MS; coloured squares indicate a modification observed on the particular fragment. These modifications can be readily assigned to single amino acid residues. Fully annotated spectra are shown in Fig. S2. $\dagger$

\section{Photoactivated platination of substance $\mathbf{P}$}

Unlike $\mathbf{K}^{3}$-Bom, SubP contains no histidine residues, and photoactivation of $\mathbf{1}+$ SubP mixture led to loss of a pyridine ligand, producing $\left(\left\{\mathrm{Pt}(\mathrm{py})(\mathrm{OH})\left(\mathrm{N}_{3}\right)\right\}\right.$ as a major peptide modification; Fig. 1a and 3). This suggests that all the types of ligands found in $\mathbf{1}$ can be released during photoirradiation, and highlights the importance of peptide sequence in determining the pathways followed during photodecomposition.

ECD MS/MS shows that $\left[\mathrm{SubP}+\left\{\mathrm{Pt}(\mathrm{py})(\mathrm{OH})\left(\mathrm{N}_{3}\right)\right\}+2 \mathrm{H}\right]^{2+}$, $\left[\mathrm{SubP}+\left\{\mathrm{Pt}(\mathrm{py})_{2}\left(\mathrm{~N}_{3}\right)\right\}+\mathrm{H}\right]^{2+}, \quad\left[\mathrm{SubP}+\left\{\mathrm{Pt}\left(\mathrm{N}_{3}\right)+\mathrm{H}\right]^{2+}, \quad\right.$ and $\left[\mathbf{S u b P}+\left\{\mathrm{Pt}(\mathrm{py})_{2}+\mathrm{H}\right\}\right]^{3+}$ species are platinated within the four $\mathrm{N}-$ terminal amino acids of the peptide (Fig. 2, Tables S5-7, Fig. S3†). $\left[\mathbf{S u b P}+\left\{\mathrm{Pt}(\mathrm{py})_{2}(\mathrm{OH})\right\}+\mathrm{H}\right]^{2+}$ species were observed only at very low intensity at all irradiation times, and reliable MS/MS fragmentation could not be obtained. ECD induced fragmentation of the N-terminal region of SubP (RPKP) is restricted by proline residues ${ }^{45}$ and the overall structure is held together via the "proline effect". ${ }^{46}$ This hampered determination of the platination sites of SubP. However, the fragmentation allowed the binding site for $\mathbf{1}$ to be located between Lys $^{3}$ and Pro. ${ }^{4}$

Interestingly, spectra from $\mathbf{1}+\mathbf{K}^{3}$-Bom mixtures after different irradiation times (30, 60, 90 or $120 \mathrm{~min}$ ) always contained the same photoproducts, increasing their overall, but not their relative intensity at longer irradiation times. However, irradiation of 1+SubP mixtures for different times showed preferential formation of different products at different times. $\left[\mathrm{SubP}+\mathrm{Pt}(\mathrm{py})(\mathrm{OH})\left(\mathrm{N}_{3}\right)+2 \mathrm{H}\right]^{2+}$ was the major product at short irradiation times, while longer irradiations of $\mathbf{1}+\mathrm{SubP}$ mixtures led to further ligand release, with $\left[\mathrm{SubP}+\mathrm{Pt}\left(\mathrm{N}_{3}\right)+\mathrm{H}\right]^{2+}$ species increasing over time. This suggests that photoreactions of 1 can continue after the formation of Pt(II) species.

\section{Methionine and tryptophan oxidation}

In addition to peptide platination; an array of oxidised products was also observed following photoactivation of 1 . Oxidised peptide species (i.e. $[\mathbf{S u b P}+\mathrm{O}+2 \mathrm{H}]^{2+},\left[\mathbf{K}^{3}-\mathbf{B o m}+\mathrm{O}+2 \mathrm{H}\right]^{2+},\left[\mathbf{K}^{3}\right.$ $\mathbf{B o m}+2 \mathrm{O}+2 \mathrm{H}]^{2+}$, and $\left[\mathbf{K}^{3}-\mathbf{B o m}+3 \mathrm{O}+2 \mathrm{H}\right]^{2+}$ ) were further studied

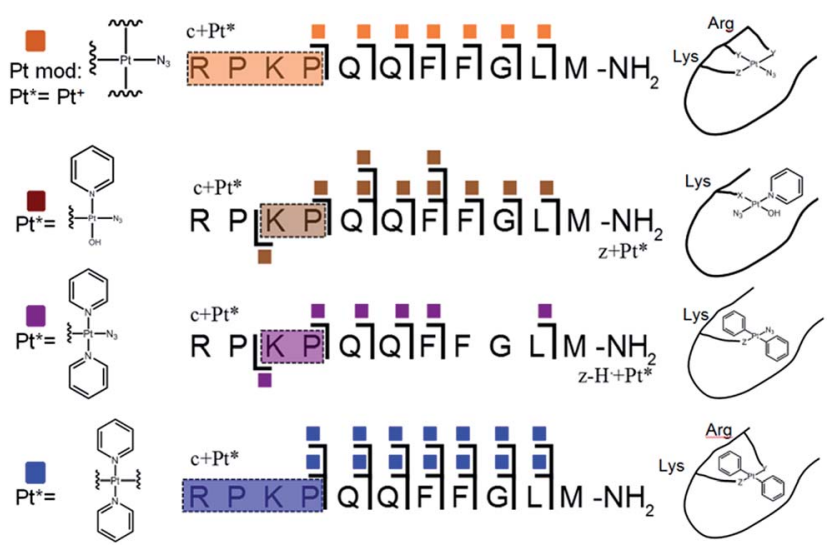

Fig. 3 Platinated SubP peptide species observed and fragmented by ECD MS/MS; coloured squares indicate a modification on the particular fragment. Fully annotated spectra are shown in Fig. S3.† 
using FT-ICR-MS and ECD MS/MS (Fig. 4 and S5, Tables S8$\mathrm{S} 11 \dagger)$. Fragmentation maps revealed that oxidation of the peptides occurs at $\mathbf{M e t}^{\mathbf{1 1}}$ for SubP and $\mathbf{M e t}^{\mathbf{1 4}}$ and $\operatorname{Trp}^{\mathbf{8}}$ for $\mathbf{K}^{\mathbf{3}}$-Bom. Methionine residues in both peptides can be oxidised to the sulfoxide, ${ }^{47}$ and further to sulfone species. ${ }^{48}$ However, MS/MS shows that photoactivation of $\mathbf{1}$ in presence of the peptides $\mathbf{K}^{\mathbf{3}}$-Bom and SubP led only to the formation of sulfoxide species.

Both mono- and di-oxidised $\mathbf{K}^{\mathbf{3}}$-Bom species showed a twoproduct fragment distribution, relating to oxidation at $\mathrm{Met}^{\mathbf{1 4}}$ or $\operatorname{Trp}^{8}$ for mono-oxidised species, and to single oxidation of both $\mathrm{Met}^{14}$ and $\operatorname{Trp}^{8}$ residues, or double oxidation of $\operatorname{Trp}^{8}$ for dioxidised species (Fig. 4, Tables S9-11, Fig. S5b-c $\dagger$ ). $\left[\mathbf{K}^{3} \text {-Bom }+3 \mathrm{O}+2 \mathrm{H}\right]^{2+}$ species showed both oxidation at $\mathbf{M e t}^{14}$ and double oxidation of $\operatorname{Trp}^{8}$ residues. Tryptophan oxidation is known to give rise to a variety of side-chain modifications, which are dependent of the nature of the oxidising agent. ${ }^{\mathbf{4 9}, 50}$ Hydroxy-tryptophan (HTRP) and $N$-formyl kynurenine(NFK) are

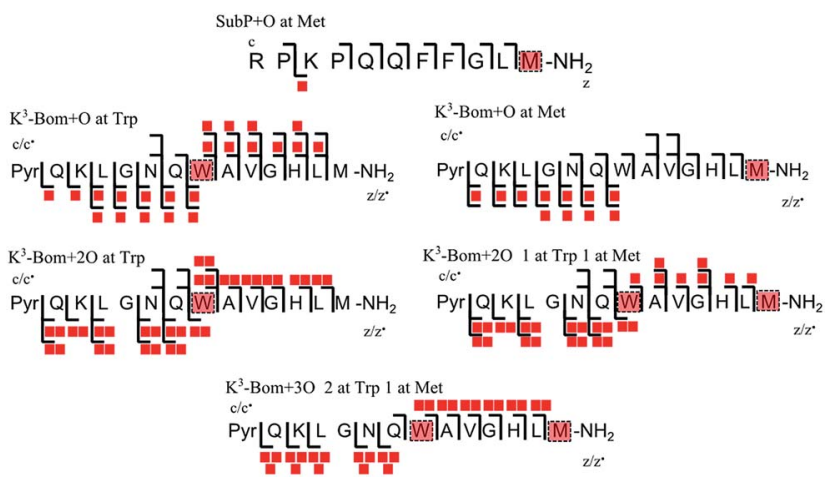

Fig. 4 Oxidised peptide species observed and fragmented by ECD MS/MS. Oxidative modifications (indicated by red squares) can be readily located on single amino acid residues (highlighted). Fully annotated tandem mass spectra can be found in the ESI (Fig. S5†).

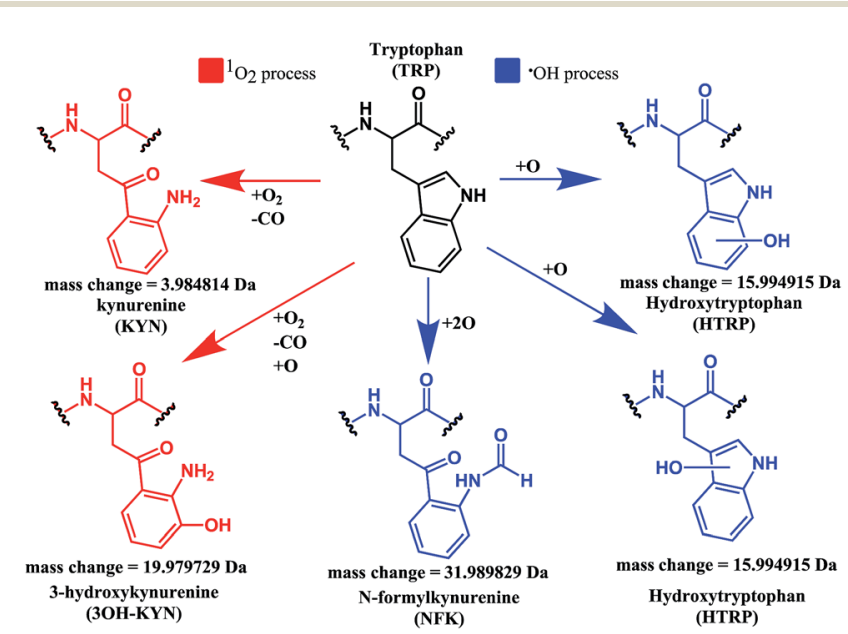

Scheme 2 Possible oxidation products arising from ${ }^{1} \mathrm{O}_{2}$ (KYN and $3 \mathrm{OH}-\mathrm{KYN}$ ) and radical (HTRP and NFK) oxidation of a tryptophan sidechain ${ }^{50,51}$ along with corresponding calculated mass changes for the modifications. Singlet oxygen induced processes are shown in red, while those induced by hydroxyl radical processes are shown in blue. formed when the 5-membered indole ring of tryptophan is attacked by hydroxyl radicals, while kynurenine (KYN) and 3hydroxy-kynurenine (3OH-KYN) arise from singlet oxygeninduced oxidation (Scheme 2). These reaction products have different mass changes compared to the original amino acid, and can be used to provide insights into the mechanism of the oxidation itself. ${ }^{50}$

UHR-FT-ICR MS spectra of $\mathbf{1}+\mathbf{K}^{\mathbf{3}}$-Bom mixtures (Fig. 1b) and the corresponding MS/MS spectra (Fig. S2a-d†) show clearly

\section{a) Complex 1+DEPMPO}

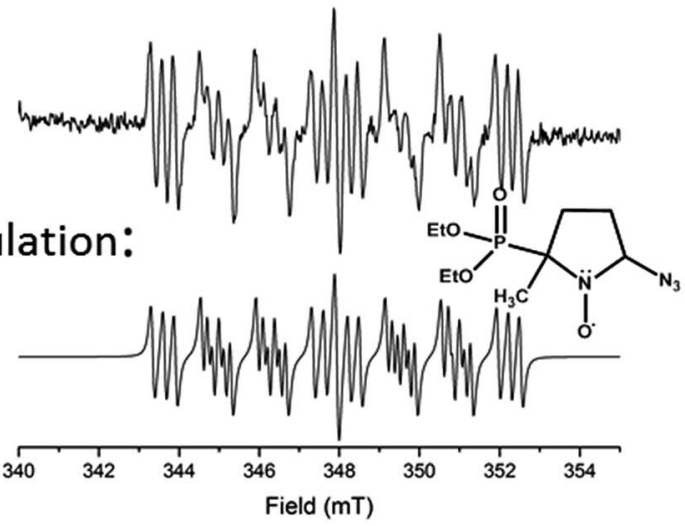

b) Complex 1+SubstanceP+DEPMPO
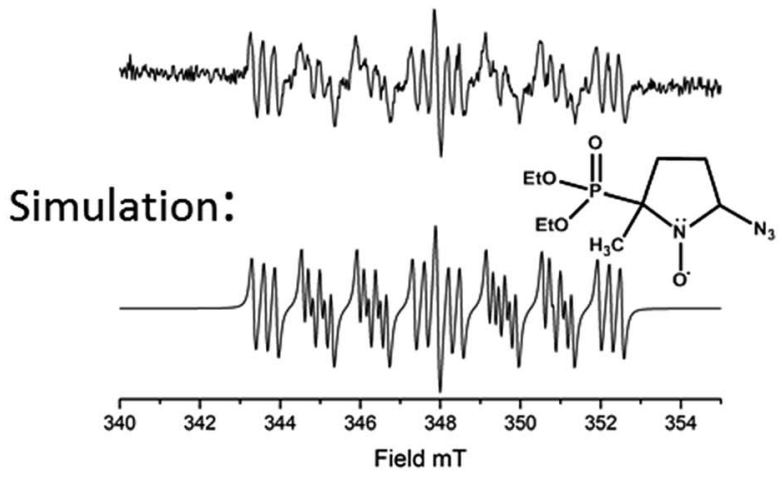

c) Complex $1+[\text { Lys }]^{3}$-Bombesin+DEPMPO

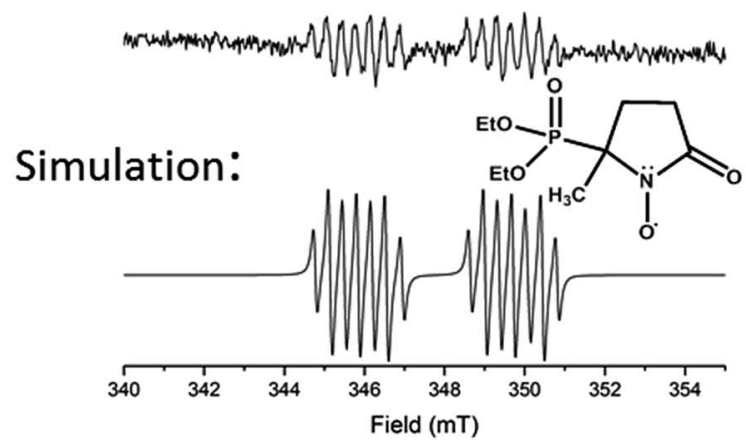

Fig. 5 EPR spectra showing the radicals trapped by DEPMPO during the photoactivation (with blue visible light) of (a) 1 (b) 1+SubP and (c) $1+\mathrm{K}^{3}-$ Bom. Inset shows simulations of corresponding spectra and the structures of the spin-trapped azidyl radicals $(a+b)$ and oxidised DEPMPO arising from attack by the high concentration of $\mathrm{OH}$ radicals produced via photoactivation of 1 with $\mathrm{K}^{3}$-Bom (c) ${ }^{52}$ 
that tryptophan oxidation leads to the formation of HTRP and NFK for the mono and di-oxidised species, respectively (+15.994915 Da and +31.989829 Da mass shifts). This suggests that hydroxyl radicals are generated when $\mathbf{1}$ is photoactivated in the presence of $\mathbf{K}^{\mathbf{3}}$-Bom, and are responsible for the oxidation of methionine and tryptophan residues. Electron transfer from an axial hydroxido ligand and an azido ligand to $\mathrm{Pt}^{\mathrm{IV}}$ can result in retention of one $\mathrm{N}_{3}$ ligand in the $\mathrm{Pt}^{\mathrm{II}}$ photo-product (Fig. 1).

\section{Detection of radicals}

EPR was used to trap radicals generated during the photoactivation of $\mathbf{1}, \mathbf{1}+\mathbf{S u b P}$, and $\mathbf{1}+\mathbf{K}^{\mathbf{3}}$-Bom with DEPMPO as the spin trap (Fig. 5, Table S12, Fig. S6†). Azidyl radicals were trapped during the photoactivation of complex 1 alone, and also from 1+SubP mixtures. However, the EPR spectra obtained from irradiation of $\mathbf{1}+\mathbf{K}^{\mathbf{3}}$-Bom mixtures were dramatically different.

Oxidised adducts of the DEPMPO trap were observed (DEPMPOX, Fig 5c). Such species can be formed by oxidation of DEPMPO-OH adducts, ${ }^{52}$ and arising from the attack by hydroxyl radicals. These studies therefore confirm that the photoreaction pathways for complex 1 can therefore not only involve electron transfer from azide ligand to $\mathrm{Pt}^{\mathrm{IV}}$ but also from an hydroxido ligand to form $\mathrm{N}_{3}$ and $\mathrm{HO}^{*}$ radicals.

\section{Effect of free tryptophan on peptide oxidation}

Reaction mixtures containing SubP+1+L-Trp and $\mathbf{K}^{\mathbf{3}}-\mathbf{B o m}+\mathbf{1}+\mathbf{L}-$ Trp (mol ratio 2 : 1 : 0.13 (peptide : drug : Trp); $31 \mu \mathrm{M}$ Trp) were irradiated with blue light $(463 \mathrm{~nm})$ for 60 and $120 \mathrm{~min}$, respectively, min and monitored by nESI-FT-ICR-MS (Table S13, Fig. S7 $\dagger$ ). Addition of Trp had little effect on the type of species produced and peptide platination observed in the photoreaction of SubP+1. However, Trp reduced the level of peptide oxidation by $29 \%$ and $95 \%$ for non-platinated and platinatedoxidised species, respectively. Trp affected more dramatically the photoreaction of $\mathbf{K}^{\mathbf{3}}$-Bom $\mathbf{+ 1}$ mixtures. Every oxidised and platinated species was reduced in intensity (except $\left[\mathbf{K}^{3}\right.$ Bom $+\mathrm{O}]^{2+}$ and $\left[\mathbf{K}^{3}-\mathbf{B o m}+3 \mathrm{O}\right]^{2+}$ ) by $32-98 \%$. This suggests that the Trp residue in $\mathbf{K}^{\mathbf{3}}$-Bom itself could play a role in determining the extent of platination of the peptide.

\section{Conclusions}

These studies show for the first time that photoactivation of the diazido $\mathrm{Pt}^{\mathrm{IV}}$ anticancer prodrug 1 can readily lead to a dual attack on peptide amino acids, either oxidation, or platination, or both. Additionally, the amino acid composition can have a dramatic effect on determining the course of the reactions. Both SubP and $\mathbf{K}^{\mathbf{3}}$-Bom were oxidised, platinated, and oxidised and platinated on photoactivation of complex $\mathbf{1}$, but the nature of the bound photoproducts of $\mathbf{1}$ and the amino acid residues modified depend on the amino acid composition of the peptide. His $^{\mathbf{1 2}}$ of $\mathbf{K}^{\mathbf{3}}$-Bom was preferentially platinated, and both pyridine ligands were retained in all the photoproducts observed, whereas for SubP, a different range of products was observed, and complex 1 released one or two pyridine ligands with apparent binding to Lys, ${ }^{3}$ and Arg $^{1}$ residues. Photoactivation led to the oxidation of specific sites in both peptides. For SubP oxidation occurred only at Met, ${ }^{\mathbf{1 1}}$ whereas for $\mathbf{K}^{\mathbf{3}}$-Bom, up to three stages of oxidation were observed: oxidation at $\mathrm{Met}^{\mathbf{1 4}}$ and a single or double oxidation of the $\operatorname{Trp}^{8}$ residue. This is the first observation of Met and Trp oxidation by this class of photoactivatable platinum anticancer complexes. Trp modification yielded hydroxytryptophan (HTRP) and N-formylkynurenine (NFK) species (Scheme 2), indicating that hydroxyl radicals are responsible for the oxidative attack. Interestingly, oxidation of Trp to NFK is also a critical step in the biological production of $\mathrm{NAD}^{+}$. The dependence of radical generation on the nature of the peptide was further confirmed by EPR spin-trapping.

The role of tryptophan as a redox-active amino acid,,$^{53}$ and the formation of HTRP and NFK species suggest that radicalbased processes might play an important role in the mechanism of action of this class of $\mathrm{Pt}^{\mathrm{IV}}$ photoactivated complexes. Such production of oxidative stress may provide some selectivity for attack on cancer cells versus normal cells, since cancer cells have malfunctioning mitochondria and are particularly susceptible to redox stress. ${ }^{54-56}$

\section{Experimental}

Substance P, [Lys $]^{3}$-bombesin, and formic acid were purchased from Sigma Aldrich Company Ltd., Dorset, UK. Low concentration Agilent tuning mix was purchased from Agilent Technologies (Santa Clara, CA). Complex 1 was synthesised and characterised as described elsewhere. ${ }^{6}$ EPR tubes were purchased from Wilmad Labglass. The spin trap 5-(diethoxyphosphoryl)-5-methyl-1-pyrroline- $N$-oxide (DEPMPO) was obtained from Enzo Life Sciences in high purity. Ultra-pure water was obtained from a Milli-Q UV III system (Milli-Q, Hertfordshire, UK).

\section{Reactions of peptides with 1}

Aliquots of aqueous solutions of Substance $\mathrm{P}(1 \mathrm{mM})$ and $[\mathrm{Lys}]^{3}$ Bombesin ( $1 \mathrm{mM}$ ) were mixed with an aqueous solution of 1 $(250 \mu \mathrm{M})$ to give solutions of $0.5: 1 \mathrm{drug}$ : peptide mol ratio. The samples were then irradiated under $463 \mathrm{~nm}$ (blue visible) light at $298 \mathrm{~K}$ for various times, before being diluted to MS concentrations $(c a .1 \mu \mathrm{M})$ and either analysed immediately or frozen at $-80{ }^{\circ} \mathrm{C}$ prior to MS analysis. Freshly prepared samples were compared to those frozen for one to several weeks and showed no observable variation in the mass spectra obtained. Reactions involving tryptophan were carried out using similar procedures as above together with the addition of aqueous tryptophan solution $(1 \mathrm{mM})$ to peptide $+\mathbf{1}$ solutions to achieve a mol ratio of $0.5: 1: 0.125$ (drug : peptide : tryptophan), i.e. concentration of tryptophan was $1 / 8^{\text {th }}$ of drug concentration, as used previously by Butler et al. ${ }^{\mathbf{1 4}}$

\section{FT-ICR mass spectrometry}

Nano-electrospray (nESI) mass spectrometry was performed on a Bruker SolariX Fourier Transform Ion Cyclotron Resonance Mass spectrometer (FT-ICR MS) fitted with a 12 tesla actively shielded magnet (Bruker Daltonics, Bremen, Germany). 
Aqueous peptide samples $(1 \mu \mathrm{M})$ were spiked with $0.3 \%$ formic acid (v/v) to aid ionisation during nESI. Solutions containing 1 (including reaction mixtures) were analysed via nESI in Milli-Q water with no added acid.

For ECD MS/MS analysis; the species of interest were isolated in the first quadrupole, externally accumulated in the collision cell for $0.1-7 \mathrm{~s}$ and then transferred to the infinity cell for Electron Capture Dissociation (ECD) fragmentation and detection. Ions in the infinity cell were irradiated with $1.3-1.6 \mathrm{eV}$ electrons from a 1.5 A hollow cathode dispenser for 50-600 ms prior to detection.

MS/MS spectra were internally calibrated using the minimal number of unmodified (peptide spectra) or modified (Pt adduct spectra) $\mathrm{c} / \mathrm{z}$ ions and the charge reduced species $[\mathrm{M}+n \mathrm{H}]^{n-1+\cdot}$ where possible (species used for calibration are marked). A dual-spray nESI experiment was also conducted using the $\left[\mathbf{K}^{\mathbf{3}}\right.$ $\mathbf{B o m}+2 \mathrm{H}]^{2+}$ ion and ions from Agilent Tune mix, utilising an incell isolation (Multi-CHEF) ${ }^{57}$ and identical ECD parameters to validate the internal calibration of the MS/MS spectra. Similar standard deviations were found for the ECD fragmentation spectra when calibrated with either fragment ions or with tunemix peaks (see ESI Fig. S8 and Table S14 $\dagger$ ). This dual-spray Multi-CHEF ECD approach was also used for some $\mathbf{1}+$ peptide reaction product ECD spectra to improve the internal calibration (spectra and calibration peaks marked accordingly).

\section{Electron paramagnetic resonance (EPR)}

EPR spectra were recorded at ambient temperature on a Bruker EMX (X-band) spectrometer fitted with a cylindrical TM110 mode cavity (Bruker 4103TM). Samples were contained in a quartz capillary tube (I.D. $1.0 \mathrm{~mm}$; O.D. $1.2 \mathrm{~mm}$; Wilmad Labglass) sealed with T-Blu Tac $®$, placed inside larger quartz tubes (O.D. $2.0 \mathrm{~mm}$ ) to achieve easy and accurate positioning of the sample inside the resonator. Typical key EPR spectrometer settings were modulation amplitude $2.0 \mathrm{G}$, microwave power $0.63 \mathrm{~mW}, 1.0 \times 10^{5}$ receiver gain, conversion time $81.92 \mathrm{~ms}$, time constant $81.92 \mathrm{~ms}$, sweep width $200 \mathrm{G}$, and a repeated number of $10 \mathrm{X}$-scans with a resolution in $Y$ of 5 or 9 . Spintrapping experiments were performed on aqueous solutions of the complex with excess of spin trap ( $1 \mathrm{mM} \mathrm{1,} 6$ mM DEPMPO) in the presence or absence of peptides $(1 \mathrm{mM})$. A visible blue light emitting diode (LED, $\lambda=463 \mathrm{~nm}, 64 \mathrm{~mW} \mathrm{~cm}^{-2}$ ) was used as the source of irradiation and placed at a distance of $8.5 \mathrm{~cm}$ from the tube in the EPR cavity. Irradiations lasted up to $2 \mathrm{~h}$, each slice corresponding to $14 \mathrm{~min}$ of irradiation (10 scans). The TM110 EPR cavity used is equipped with a grid on one side allowing optical access (ca., 50\%) transmission. The refractive index of quartz is approximately 1.55 ; hence at normal incidence approximately $5 \%$ of the incident light is reflected at an air quartz interface. EPR spectra were analysed and simulated using the EASYSPIN software. ${ }^{58}$

\section{UV-vis spectroscopy}

Aqueous solutions of $1(60 \mu \mathrm{M})$, SubP $(120 \mu \mathrm{M}), \mathbf{K}^{3}$-Bom $(120 \mu \mathrm{M}), \mathbf{1}(60 \mu \mathrm{M})+\mathbf{S u b P}(120 \mu \mathrm{M})$, and $\mathbf{1}(60 \mu \mathrm{M})+\mathbf{K}^{\mathbf{3}}$-Bom $(120 \mu \mathrm{M})$ were prepared and irradiated as above, then studied using a Cary 300 scan UV-visible spectrophotometer (Agilent, California, US). Solutions were analysed in quartz cuvettes (0.5 $\mathrm{mL}, 1 \mathrm{~cm}$ path length), with scanning in the region of $200-800 \mathrm{~nm}$ at a rate of $10 \mathrm{~nm} \mathrm{~s}^{-1}\left(600 \mathrm{~nm} \mathrm{~min}^{-1}\right)$, average time $=0.1 \mathrm{~s}$, data interval $1 \mathrm{~nm}$.

\section{Conflicts of interest}

There are no conflicts to declare.

\section{Acknowledgements}

We thank the EPSRC Warwick Centre for Analytical Science (grant no. EP/F034210/1, and EP/J000302), the European Research Council (grant no. 247450), Bruker Daltonics, Warwick Collaborative Postgraduate Research Scholarships (WCPRS) and the Magnetic Resonance Centre (Warwick University) for EPR support. The authors also thank Mr Cookson K. C. Chiu for helpful discussions.

\section{References}

1 J. Pracharova, L. Zerzankova, J. Stepankova, O. Novakova, N. J. Farrer, P. J. Sadler, V. Brabec and J. Kasparkova, Chem. Res. Toxicol., 2012, 25, 1099-1111.

2 N. J. Farrer and P. J. Sadler, Aust. J. Chem., 2008, 61, 669.

3 S. Betanzos-Lara, L. Salassa, A. Habtemariam, O. Novakova, A. M. Pizarro, G. J. Clarkson, B. Liskova, V. Brabec and P. J. Sadler, Organometallics, 2012, 31, 3466-3479.

4 K. S. Lovejoy and S. J. Lippard, Dalton Trans., 2009, 1065110659.

5 B. S. Howerton, D. K. Heidary, E. C. Glazer, D. K. Heidary and E. C. Glazer, 2012, 3-6.

6 N. J. Farrer, J. a. Woods, L. Salassa, Y. Zhao, K. S. Robinson, G. Clarkson, F. S. Mackay and P. J. Sadler, Angew. Chem., Int. Ed. Engl., 2010, 49, 8905-8908.

7 S. B. Brown, E. A. Brown and I. Walker, Lancet Oncol., 2017, 5, 497-508.

8 F. S. Mackay, J. A. Woods, H. Moseley, J. Ferguson, A. Dawson, S. Parsons and P. J. Sadler, Chemistry, 2006, 12, 3155-3161.

9 A. F. Westendorf, J. A. Woods, K. Korpis, N. J. Farrer, L. Salassa, K. Robinson, V. Appleyard, K. Murray, R. Grunert, A. M. Thompson, P. J. Sadler and P. J. Bednarski, Mol. Cancer Ther., 2012, 11, 1894-1904.

10 K. Deng, Z. L. Chen, X. P. Zhou, W. F. Wang, X. X. Yang and J. Tian, Chin. J. Chem., 2008, 26, 202-207.

11 F. S. Mackay, J. A. Woods, P. Heringová, J. Kaspárková, A. M. Pizarro, S. A. Moggach, S. Parsons, V. Brabec and P. J. Sadler, Proc. Natl. Acad. Sci. U. S. A., 2007, 104, 2074320748.

12 P. J. Bednarski, F. S. Mackay and P. J. Sadler, Anti Canc. Agents Med. Chem., 2007, 7, 75-93.

13 A. M. Pizarro and P. J. Sadler, Biochimie, 2009, 91, 1198-1211. 14 J. S. Butler, J. A. Woods, N. J. Farrer, M. E. Newton and P. J. Sadler, J. Am. Chem. Soc., 2012, 134, 16508-16511. 15 L. Ronconi and P. J. Sadler, Chem. Commun., 2008, 235-237. 
16 C. M. Ryan, P. Souda, S. Bassilian, R. Ujwal, J. Zhang, J. Abramson, P. Ping, A. Durazo, J. U. Bowie, S. S. Hasan, D. Baniulis, W. a. Cramer, K. F. Faull and J. P. Whitelegge, Mol. Cell. Proteomics, 2010, 9, 791-803.

17 S. Yin and J. A. Loo, Int. J. Mass Spectrom., 2011, 300, 118122.

18 F. Xu, Q. Xu, X. Dong, M. Guy, H. Guner, T. A. Hacker and Y. Ge, Int. J. Mass Spectrom., 2011, 305, 95-102.

19 C. S. Allardyce, P. J. Dyson, J. Coffey and N. Johnson, Rapid Commun. Mass Spectrom., 2002, 16, 933-935.

20 H. Li, T. Lin, S. L. Van Orden, Y. Zhao, M. P. Barrow, A. M. Pizarro, Y. Qi, P. J. Sadler and P. B. O'Connor, Anal. Chem., 2011, 9507-9515.

21 S. K. Weidt, C. L. Mackay, P. R. R. Langridge-Smith and P. J. Sadler, Chem. Commun., 2007, 2, 1719-1721.

22 C. G. Hartinger, Y. O. Tsybin, J. Fuchser and P. J. Dyson, Inorg. Chem., 2008, 47, 17-19.

23 A. E. Egger, C. G. Hartinger, H. Ben Hamidane, Y. O. Tsybin, B. K. Keppler and P. J. Dyson, Inorg. Chem., 2008, 47, 1062610633.

24 L. Messori, L. Cubo, C. Gabbiani, A. Álvarez-Valdés, E. Michelucci, G. Pieraccini, C. Ríos-Luci, L. G. León, J. M. Padrón, C. Navarro-Ranninger, A. Casini and A. G. Quiroga, Inorg. Chem., 2012, 51, 1717-1726.

25 A. Casini, C. Gabbiani, E. Michelucci, G. Pieraccini, G. Moneti, P. J. Dyson and L. Messori, J. Biol. Inorg Chem., 2009, 14, 761-770.

26 M. Groessl, Y. O. Tsybin, C. G. Hartinger, B. K. Keppler and P. J. Dyson, J. Biol. Inorg Chem., 2010, 15, 677-688.

27 M. V. Babak, S. M. Meier, K. V. M. Huber, J. Reynisson, A. A. Legin, M. A. Jakupec, A. Roller, A. Stukalov, M. Gridling, K. L. Bennett, J. Colinge, W. Berger, P. J. Dyson, G. Superti-Furga, B. K. Keppler and C. G. Hartinger, Chem. Sci., 2015, 6, 2449-2456.

28 Y. Lin, Y. Huang, W. Zheng, K. Wu, Q. Luo, Y. Zhao, S. Xiong and F. Wang, J. Inorg. Biochem., 2015, 146, 44-51.

29 Y. Qi, Z. Liu, H. Li, P. J. Sadler and P. B. O'Connor, Rapid Commun. Mass Spectrom., 2013, 27, 2028-2032.

30 C. A. Wootton, C. Sanchez-Cano, H.-K. Liu, M. P. Barrow, P. J. Sadler and P. B. O'Connor, Dalton Trans., 2015, 44, 3624-3632.

31 H. Li, T. Lin, S. L. Van Orden, Y. Zhao, M. P. Barrow, A. M. Pizarro, Y. Qi, P. J. Sadler and P. B. O. Connor, Anal. Chem., 2011, 83, 9507-9515.

32 H. Li, Y. Zhao, H. I. A. Phillips, Y. Qi, T.-Y. Lin, P. J. Sadler and P. B. O'Connor, Anal. Chem., 2011, 83, 5369-5376.

33 M. Wenzel and A. Casini, Coord. Chem. Rev., 2017, 352, 432460.

34 R. Zubarev, N. L. Kelleher and F. W. McLafferty, J. Am. Chem. Soc., 1998, 7863, 3265-3266.
35 R. A. Zubarev, Curr. Opin. Biotechnol., 2004, 15, 12-16.

36 B. Ohlsson, N. Fredang and J. Axelson, Scand. J. Gastroenterol., 1999, 34, 1224-1229.

37 D. Singh, D. D. Joshi, M. Hameed, J. Qian, P. Gascón, P. B. Maloof, A. Mosenthal and P. Rameshwar, Proc. Natl. Acad. Sci. U. S. A., 2000, 97, 388-393.

38 D. Gibson and C. E. Costello, Eur. J. Mass Spectrom., 1999, 510, 501-510.

39 T. Zhao and F. L. King, J. Am. Soc. Mass Spectrom., 2009, 20, 1141-1147.

40 C. G. Hartinger, W. H. Ang, A. Casini, L. Messori, B. K. Keppler and P. J. Dyson, J. Anal. At. Spectrom., 2007, 22, 960 .

41 N. Leymarie, C. E. Costello and P. B. O'Connor, J. Am. Chem. Soc., 2003, 125, 8949-8958.

42 E. A. Syrstad and F. Turecek, J. Am. Soc. Mass Spectrom., 2005, 16, 208-224.

43 F. Turecek, J. Am. Chem. Soc., 2003, 125, 5954-5963.

44 B. Ganisl and K. Breuker, ChemistryOpen, 2012, 1, 260-268.

45 K. O. Zhurov, L. Fornelli, M. D. Wodrich, Ü. a. Laskay and Y. O. Tsybin, Chem. Soc. Rev., 2013, 42, 5014-5030.

46 J. Pan, J. Han and C. H. Borchers, Int. J. Mass Spectrom., 2012, 325-327, 130-138.

47 E. R. Stadtman, H. Van Remmen, A. Richardson, N. B. Wehr and R. L. Levine, Biochim. Biophys. Acta, Proteins Proteomics, 2005, 1703, 135-140.

48 A. N. Skvortsov, V. E. Zavodnik, A. I. Stash, V. K. Bel'skii and N. K. Skvortsov, Russ. J. Org. Chem., 2003, 39, 170-175.

49 J. E. Plowman, S. Deb-Choudhury, A. J. Grosvenor and J. M. Dyer, Photochem. Photobiol. Sci., 2013, 12, 1960-1967.

50 E. L. Finley, J. Dillon, R. K. Crouch and K. L. Schey, Protein Sci., 1998, 7, 2391-2397.

51 S. W. Taylor, E. Fahy, J. Murray, R. a. Capaldi and S. S. Ghosh, J. Biol. Chem., 2003, 278, 19587-19590.

52 J.-L. Clément, B. C. Gilbert, A. Rockenbauer and P. Tordo, J. Chem. Soc., Perkin Trans. 2, 2001, 1463-1470.

53 C. Shih, A. K. Museth, M. Abrahamsson, A. M. BlancoRodriguez, A. J. Di Bilio, J. Sudhamsu, B. R. Crane, K. L. Ronayne, M. Towrie, A. Vlcek, J. H. Richards, J. R. Winkler and H. B. Gray, Science, 2008, 320, 1760-1762. 54 J. S. Carew and P. Huang, Mol. Cancer, 2002, 1, 9.

55 K. F. Macleod, M. L. Boland, A. H. Chourasia and K. F. Macleod, Front. Oncol., 2013, 3, 1-28.

56 M. L. Circu and T. Y. Aw, Free Radical Biol. Med., 2010, 48, 749-762.

57 L. J. de Koning, N. M. M. Nibbering, S. L. van Orden and F. H. Laukien, Int. J. Mass Spectrom., 1997, 165, 209-219. 58 S. Stoll and A. Schweiger, J. Magn. Reson., 2006, 178, 42-55. 